\title{
The microbial community of a passive biochemical reactor treating arsenic, zinc, and sulfate-rich seepage
}

\author{
Susan Anne Baldwin ${ }^{1 *}$, Maryam Khoshnoodi ${ }^{1}$, Maryam Rezadehbashi ${ }^{1}$, Marcus Taupp ${ }^{2}$, Steven Hallam ${ }^{2}$, \\ Al Mattes ${ }^{3}$ and Hamed Sanei ${ }^{4,5,6}$
}

${ }^{1}$ Chemical and Biological Engineering, University of British Columbia, Vancouver, BC, Canada

${ }^{2}$ Department of Microbiology and Immunology, University of British Columbia, Vancouver, BC, Canada

${ }^{3}$ NatureWorks Remediation Corporation, Rossland, BC, Canada

${ }^{4}$ Geological Survey of Canada, Calgary, $A B$, Canada

${ }^{5}$ Center for Energy Technologies (CET), AU-Herning, Aarhus University, Herning, Denmark

${ }^{6}$ Department of Geoscience, University of Calgary, Calgary, AB, Canada

\section{Edited by:}

Kartik Chandran, Columbia University, USA

\section{Reviewed by:}

Giridhar Upadhyaya, University of

Michigan, USA

Daniel Puyol, University of

Queensland, Australia

*Correspondence:

Susan Anne Baldwin, 2360 East Mall,

Vancouver, BC, Canada

e-mail: sbaldwin@mail.ubc.ca
Sulfidogenic biochemical reactors (BCRs) for metal removal that use complex organic carbon have been shown to be effective in laboratory studies, but their performance in the field is highly variable. Successful operation depends on the types of microorganisms supported by the organic matrix, and factors affecting the community composition are unknown. A molecular survey of a field-based BCR that had been removing zinc and arsenic for over 6 years revealed that the microbial community was dominated by methanogens related to Methanocorpusculum sp. and Methanosarcina sp., which co-occurred with Bacteroidetes environmental groups, such as Vadin HA17, in places where the organic matter was more degraded. The metabolic potential for organic matter decomposition by Ruminococcaceae was prevalent in samples with more pyrolyzable carbon. Rhodobium-and Hyphomicrobiumrelated genera within the Rhizobiales order that have the metabolic potential for dark hydrogen fermentation and methylotrophy, and unclassified Comamonadaceae were the dominant Proteobacteria. The unclassified environmental group Sh765B-TzT-29 was an important Delta-Proteobacteria group in this BCR that co-occurred with the dominant Rhizobiales operational taxonomic units. Organic matter degradation is one driver for shifting the microbial community composition and therefore possibly the performance of these bioreactors over time.

Keywords: biochemical reactor, microbial ecology, organic matter degradation, metals, water treatment, bioremediation, sequencing, Rock-Eval-6

\section{INTRODUCTION}

Using passive or semi-passive microbial reactors to remove metals from mine or metallurgical waste seepage is very attractive due to the vast repertoire of microbial metabolic responses to metals (Gadd, 2010). Both direct and indirect mechanisms make remediation of metal contaminated water successful. Bioreactors are provided with an organic-rich material, usually a waste product from forestry, pulp and paper, agriculture, or food industries that provides a supply of electron donors to fuel microbial consortia (Lindsay et al., 2008, 2011; Mattes et al., 2011; Schmidtova and Baldwin, 2011). Microbial activity consumes oxygen to create anaerobic and reducing conditions under which several microbial processes, as well as favorable geochemical conditions, occur that promote metal immobilization: fermentative organisms provide electron donors from decomposing complex organic matter; sulfate- and metal-reducing microbes use these electron donors to produce products that lead to metal immobilization (Jalali and Baldwin, 2000; Stolz et al., 2006; Khoshnoodi et al., 2013); membranebound metal transporters assimilate metals into microbial cells where they can be methylated and volatilized, accumulated, or reduced to other redox states (Zhang and Frankenberger, 2000;
Bentley and Chasteen, 2002; Amoozegar et al., 2012); extrapolymeric substances and cell walls possess binding moieties for metal ions that act as nucleation sites for biosorption and precipitation (Mullen et al., 1989; Jalali and Baldwin, 2000; French et al., 2013). Despite this myriad of avenues for metal transformation and immobilization, biochemical reactors (BCRs) for treatment of mining-influenced water at industrial sites are often beset with sub-optimal performance or even completely fail to reliably meet water quality objectives.

The type of nutrient source used is key and much previous work has taken place to compare different types and combinations of waste materials, such as manure, compost, wood, sawdust, silage, leaf litter, hay, and pulp and paper biosolids, for example, for their efficacy at supporting sulfate-reducing bacteria and removing metals (Waybrant et al., 1998; Zagury et al., 2006; Lindsay et al., 2008; Neculita and Zagury, 2008; Schmidtova and Baldwin, 2011). Attempts in these studies to correlate properties of the organic material such as their carbon and nitrogen content or amount of easily available or more recalcitrant material to sulfate-reduction or metal removal rate have been inconsistent. Most tests using these materials were carried out for only short durations (days, 
months) and very little is known about how rapidly they would decompose when used in actual BCRs that are expected to operate for years on end. The long-term efficacy of carbon sources used in these bioreactors has been rarely studied.

Despite their perceived role in metal removal mechanisms, the microbial communities supported by these organic materials in BCRs have seldom been characterized. Operators can only speculate on what the reasons for poor operation could be when these systems are not performing well. More work has been done on microbes in so-called active treatment processes, where definedcarbon sources are used in tank-based bioreactors (Dar et al., 2007). Only recently have attempts been made to characterize the much more diverse microbial communities of complex carbon source BCRs (Hiibel et al., 2008), and the importance of the starting microbial community was highlighted as one determinant for successful performance (Pereyra et al., 2008). To our knowledge, there are no studies correlating microbial community composition to organic matter characteristics in field-based metal-removing BCRs. As the organic material degrades over time, the supply of electron donors may change as the more degradable material becomes depleted. This is bound to impact the microbial community composition, which might contribute to different processes taking place in the bioreactor, some of which could compromise reactor performance. In this work, we characterize the microbial community composition in a BCR treating metallurgical waste landfill seepage that had been operating continuously for 6 years since being rebuilt with fresh pulp and paper mill biosolids as the nutrient source. To capture the relative abundance and diversity of the microbial community, samples were taken from the BCR at different spatial locations and at different times of the year. Two molecular methods were employed based on long reads of the small subunit ribosomal ribonucleic acid sequences (SSU rRNA) for high fidelity and high-throughput sequencing of smaller SSU rRNA fragments for greater depth. Microbial community composition correlation with environmental parameters and organic matter properties was evaluated.

\section{MATERIALS AND METHODS SITE CHARACTERIZATION AND SAMPLE COLLECTION}

The BCR was located in British Columbia, Canada at $49.115763^{\circ} \mathrm{N}$, $-117.737118^{\circ} \mathrm{E}$, and was the first in a series of sub-surface and surface flow wetlands (Mattes et al., 2011; Figure 1). Influent entered at the bottom of the BCR and flowed upwards through the reactive matrix of pulp and paper biosolids, manure, sand, and crushed pea-sized limestone (Figure S1 in Supplementary Material). Samples were removed during three different seasons in July 2008, April 2009, and October 2009. Saturated material was accessed by drilling three boreholes each time through a soil cover. Cores were removed inside $2-\mathrm{cm}$ internal diameter poly vinyl chloride pipes, which were capped immediately and frozen using liquid nitrogen.

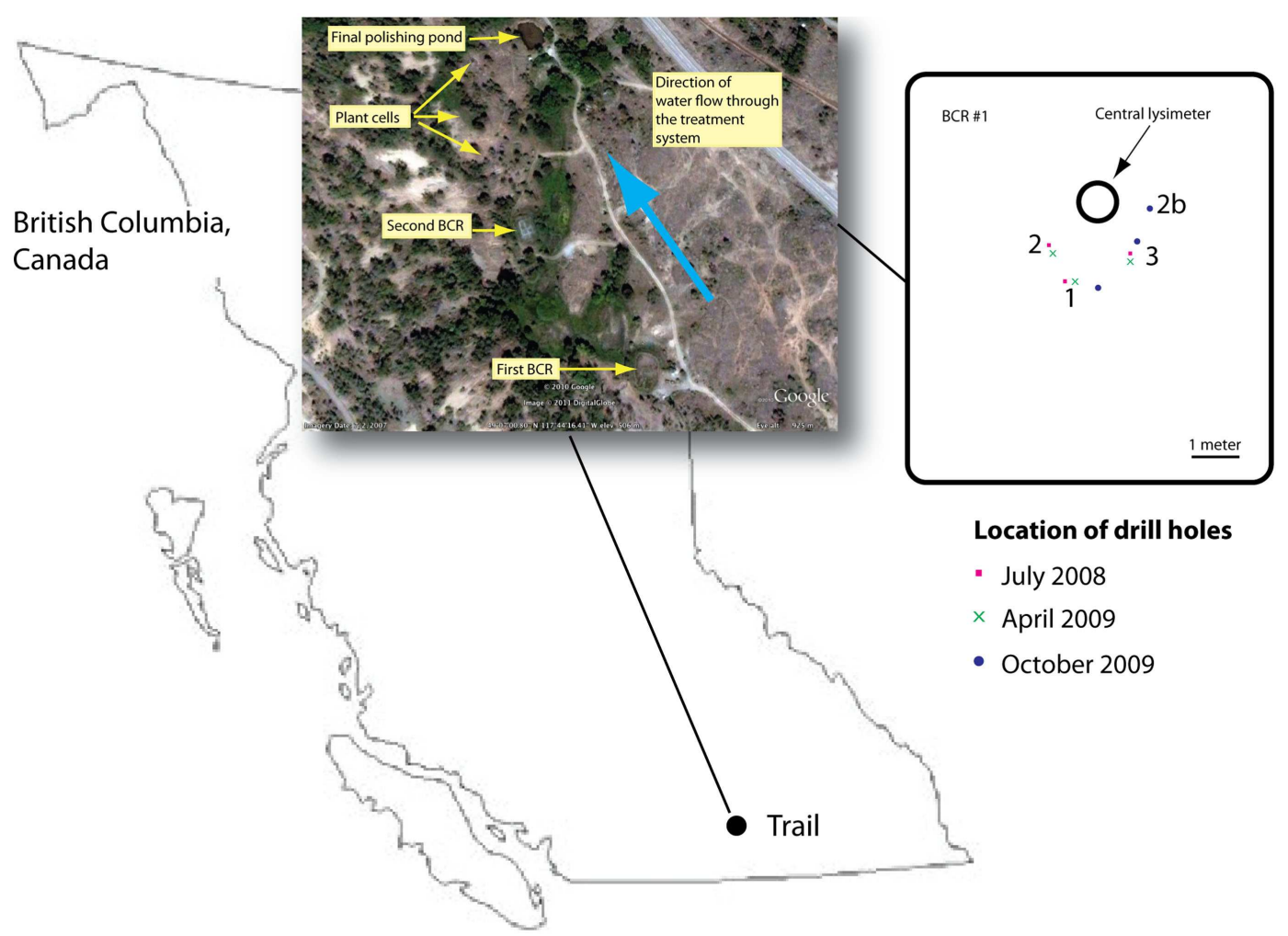

FIGURE 1 | Location of the BCR in British Columbia, Canada. Inset provides an aerial view of the whole treatment train according to Google Earth. Second inset is a map of the first BCR that was sampled in this study showing the locations of the drill holes. Drill hole location was chosen so as to avoid damaging internal baffles. 
In the laboratory, cores were sectioned into 5-cm intervals while still frozen and each section was homogenized by grinding under liquid nitrogen. Homogenized sections were stored at $-80^{\circ} \mathrm{C}$ until DNA extraction.

\section{DNA EXTRACTION AND PREPARATION OF CLONE LIBRARIES AND PYROTAG LIBRARIES}

Aliquots from each homogenized $5-\mathrm{cm}$ interval for all depths and cores were used for extraction of DNA using methods described in detail in the Supplemental Material. Clone libraries for the middle section $(20-30 \mathrm{~cm}$ depth) of each of the nine cores were produced for Archaea and bacteria using primers targeting the archaeal domain A4F (5'-TCCGGTTGATCCTGCCRG) and U1492R (5'-GGTTACCTTGTTACGACTT) and the bacterial domain B27F (5'-AGAGTTTGATCCTGGCTCAG) and U1492R (5'GGTTACCTTAGTTACGACTT), respectively, using gradient PCR methods described in detail in the Supplemental Material. Cloned inserts were sequenced bi-directionally with M13F (5'-GTAAAACGACGGCCAG) and M13R (5'CAGGAAACAGCTATGAC) primers at the Michael Smith Genome Sciences Centre (Vancouver, BC, Canada). Sequences were assembled and checked for chimeras as described in the Supplemental Material.

Different aliquots of the homogenized samples were used for the pyrotag libraries. The DNA was extracted using the Power Soil DNA isolation Kit (MoBio Laboratories Incorporation, Carlsbad, CA, USA, Cat No:12888-100) following the manufacturer's instructions. DNA from adjacent $5-\mathrm{cm}$ intervals was combined to yield 38 samples from all cores and all depths that were used for PCR amplification of the V6-V8 variable SSU rRNA region: 926f ( $5^{\prime}$ AAACTYAAAKGAATTGRCGG $\left.3^{\prime}\right)$ and 1392r (5' ACGGGCGGTGTGTRC $3^{\prime}$ ) as described in detail in the Supplemental Material. Purified PCR products were sent to the McGill University Innovation Centre (Montréal, QC, Canada) for pyrosequencing using a Roche GS-FLX Titanium Series sequencer. Pyrotag reads were filtered using the following quality control criteria: minimum length $200 \mathrm{bp}$, no ambiguous base reads, no missing quality scores, mean quality score greater than 25, no more than six nucleotide length homopolymer runs, and no mismatches in reverse primer. Raw pyrotag sequences were deposited in the sequence read archive of the National Center for Biotechnology Information (NCBI) under project PRJNA239169 (Pruitt et al., 2009).

\section{BIOINFORMATICS AND STATISTICS}

The Mothur pipeline (Schloss et al., 2009) was executed for clustering the Archaeal clone library sequences into operational taxonomic units (OTUs) using a 97\% sequence homology cutoff. A representative sequence for each OTU was picked based on the most abundant read in the OTU bin. Only high-quality SSU rRNA clone reads were used for the analysis and the representative sequences for each OTU were deposited in the NCBI database (Pruitt et al., 2009) (KM213856-KM213864). Qiime (Caporaso et al., 2010) was used to cluster the bacteria clone library sequences and pyrotag reads into OTUs using the methods cd-hit (Li and Godzik, 2006) and usearch (Edgar, 2010), respectively, with 90, 94, or 97\% homology cut-offs. Each OTU was assigned a taxonomic classification using BLASTN of the representative sequences to the Silva version 111 curated reference dataset (Quast et al., 2013). Representative sequences for the bacteria clone library 97\% OTUs were deposited in the NCBI database (KM250907-KM251172). Phylogenetic trees were constructed using MUSCLE version 3.8.31 for alignment (Edgar, 2004) and the maximum likelihood method for tree building [PHYML (Guindon et al., 2009) with the nucleotide substitution model HKY85 (Hasegawa et al., 1985) and 100 bootstraps]. Sequences for closely related cultured species and environmental clones were found by BLASTN to the NCBI refseq and nucleotide databases (Pruitt et al., 2009), respectively.

Microbial community compositions were compared using two statistical approaches: (1) weighted UniFrac (Lozupone and Knight, 2005) based on phylogenetic distances with principal coordinate analysis (PCoA) using non-metric multidimensional scaling (NMDS) through the R phyloseq wrapper version 1.6.1 (McMurdie and Holmes, 2013) and (2) Bray-Curtis dissimilarity (Jones et al., 2009) visualized on a detrended correspondence analysis (DCA) PCoA diagram produced with the $\mathrm{R}$ package vegan version 2.0-10. The latter results were fit to a linear model containing the Rock-Eval-6 variables to test for statistically significant correlations using $\mathrm{R}$ (vegan). Cooccurrence of taxonomic groups (94\% homology cut-off OTUs) was assessed using Pearson's correlation of pair-wise OTU read counts. Associations greater than 0.80 correlation and $p$-value less than 0.05 were visualized on a network diagram produced with the $\mathrm{R}$ package igraph through the wrapper phyloseq (McMurdie and Holmes, 2013).

\section{CHEMICAL ANALYSIS}

Influent and effluent metal and sulfate concentrations were measured every 2 weeks by the operators using inductively coupled mass spectroscopy (ICP-MS) in an industrial metallurgical laboratory. At the time of sampling, pore water $\mathrm{pH}$, temperature, dissolved oxygen, and oxidation-reduction potential were measured using a 6600V2 sonde with appropriate probes (YSI Inc., Yellow Springs, OH, USA). Pore water nitrite, nitrate, ammonia, total phosphorous, sulfide, and $\mathrm{Fe}^{2+}$ were measured in situ using field kits (Hach company, Loveland, CO, USA; CHEMetrics, Midland, VA, USA). Samples were preserved using $0.3 \%$ zinc acetate for sulfate analysis later in the laboratory using standard method 4500- $\mathrm{SO}_{4}^{2-}$ (Eaton et al., 2005). The degree of organic matter degradation was deduced using the pyrolysis technique Rock-Eval-6 (Behar et al., 2001) on 33 samples. This technique characterizes the organic matter in terms of several fractions: S1 refers to the light hydrocarbons (HCs) that pyrolyze first with units of milligram HC per milligram total organic carbon (TOC); S2 contains organic matter that is removed next. Pyrolyzable carbon (PC) is the sum of $\mathrm{S} 1$ and $\mathrm{S} 2$ plus $\mathrm{CO}$ and $\mathrm{CO}_{2}$ evolved during pyrolysis. Residual carbon (RC) refers to the remaining organic matter that is combusted. Additionally, mineral carbon (MINC) is quantified also in the Rock-Eval-6 process. More details and example Rock-Eval-6 spectra are given in the Supplementary Material. 


\section{RESULTS \\ BCR PERFORMANCE AND ENVIRONMENTAL CONDITIONS}

Dissolved arsenic, zinc, and sulfate influent concentrations averaged $2.3(1.0) \mathrm{mg} / \mathrm{L}, 40(8) \mathrm{mg} / \mathrm{L}$, and $650(100) \mathrm{mg} / \mathrm{L}$, respectively (Figure 2). On average, $47.8 \%$ arsenic and $34.2 \%$ zinc were removed but the average sulfate concentration increased by $9.0 \%$. Influent flow rates averaged $477.8 \mathrm{~m}^{3} /$ month except for August 2008 when an exceptional amount of seepage $\left(1,703 \mathrm{~m}^{3}\right)$ entered the system. Based on estimated hydraulic retention times ( $\sim 4$ weeks) through each of the stages in the whole treatment system, most of the zinc was removed in the first BCR (Figure 2D). During sampling, conditions inside the BCR were reducing (ORP less than $-112 \mathrm{mV}$ ), with circum-neutral $\mathrm{pH}(5.6-7.5)$ and low amounts of dissolved oxygen $(0-1.5 \mathrm{mg} / \mathrm{L}$; Table 1). Sulfide was detected in the pore water in July only $(1.1-3.5 \mathrm{mg} / \mathrm{L})$. Sulfate concentrations in the pore water varied from 80 to $600 \mathrm{mg} / \mathrm{L}$ (Table 1). Dissolved oxygen in the pore water was lowest (below the detection limit) in July, when temperatures were highest $\left(17.6^{\circ} \mathrm{C}\right.$ average). The coldest temperatures encountered were in April $\left(7.1^{\circ} \mathrm{C}\right.$ average). There were no significant seasonal variations in $\mathrm{pH}$ or ORP. Although there were no significant differences in metal removal with season according to the influent and effluent data collected by the operator (Figure 2), the pore water chemistry differed. The presence of sulfide and lower concentrations of sulfate and metals during July 2008 than the other months suggested that the bioreactor was more active in terms of sulfate-reduction when the temperatures were warmer and the DO lower. Total phosphorous concentrations in April were lower than those measured in July and October, which might have been a nutrient limitation at that time.

\section{SOLIDS CHEMISTRY}

Organic matter (OM) characteristics were determined so as to estimate the degree of degradability of the matrix at the time of sampling. Rock-Eval-6 is a pyrolysis method used to study the composition of organic material with different maturities; most often coal and other HCs, but also organic matter in soils and sediments (Behar et al., 2001). The TOC measured in the Rock-Eval-6 analysis in the BCR core samples averaged $4.63 \pm 2.45 \mathrm{wt} \%$ compared with $11.1 \pm 0.9 \mathrm{wt} \%$ in fresh matrix of a similar composition to that in the BCR. The bulk of the pyrolyzable compounds were liberated under the S2 peak (Table 2), which was typically broad in contrast to the narrower S1 peak (Sebag et al., 2006; Figure S2 in Supplementary Material). Both peaks contained shoulders indicating mixtures of compounds. Pyrolyzable material under the S1 peak was roughly half that of S2 in the BCR samples. The average ratio of the $\mathrm{S} 1$ to $\mathrm{S} 2$ fraction was 0.45 compared to 0.59 for the fresh biosolids. Less than half of the TOC was as the PC fraction, which was lower than that in a fresh pulp mill biosolids sample containing sand and limestone in the same ratios as was in the original BCR mixture.

\section{OVERALL MICROBIAL DIVERSITY}

A total of 416 Archaea and 730 bacteria clone library SSU rRNA sequences were obtained yielding 9 and 268, respectively, 97\% homology cut-off OTUs. After quality control, 208,483 pyrotag reads were obtained, with the number of reads per sample varying from 1,083 to 10,356 . The $1,66797 \%$ homology pyrotag OTUs were classified into a total of 37 phyla within the Archaea (2), Bacteria (32), and Eukaryota (3) domains. The pyrotag reads revealed that 15 phyla dominated with Euryarchaeota-related sequences the most abundant (Figure 3). Proportional representation of the phyla varied across the samples. In some cases (Holes 1 and 3 in July and Hole 2 in October), the percentage of Euryarchaeota-related reads increased with depth, but this was not statistically significant overall. There were no statistically significant differences between the microbial community compositions of different seasons, with the same dominant 14 phyla represented throughout.

The Archaea clone SSU rRNA sequences formed five major clades (Figure S3 in Supplementary Material). The majority of sequences were classified as Class II methanogens in the orders Methanomicrobiales and Methanosarcinales closely related to Methanocorpusculum labreanum, M. parvum, Methanosarcina vacuolata, and $M$. barkeri. Close environmental relatives came from anaerobic digesters (Godon et al., 1997) and HC environments, such as tar pits, biodegraded oil reservoirs, and coal beds (Figure S3 in Supplementary Material; Zhao et al., 1989; Grabowski et al., 2005a; Strapoc et al., 2008). Pyrotag sequences revealed that family-level Methanocorpusculaceae-related OTUs dominated the overall microbial community (Figure 4A) with Methanocorpusculum as the most highly represented genus (Figure S4 in Supplementary Material). Unclassified Methanobacteriaceae were highly prevalent although none of the clone library sequences were classified in this family.

Most bacteria were classified into the phyla Firmicutes, Bacteroidetes, Proteobacteria, and Spirochetes according to both the clone library and pyrotags (Figure 3; Figure S5 in Supplementary Material). Additionally, Candidate Division environmental groups were present, such as WS6 and OP11, within which no species have been cultured or characterized. These are widely represented in many environments including bioreactor sludge as well as soils (Dinis et al., 2011; Youssef et al., 2011). Apart from the Euryarchaeota, the most highly represented genus-level OTUs were Treponema-related (in the Spirochetes phylum; Figure S5 in Supplementary Material).

Bacteria associated with organic matter digestion, such as Ruminococcaceae and Erysipelotrichaceae were highly represented in the Firmicutes phylum (Figure 4B; Figure S6 in Supplementary Material). In particular, one genus-level OTU classified as Erysipelotrichaceae was the seventh most prevalent (Figure S4 in Supplementary Material). Clone library sequences related to cellulose degrading and fermenting Clostridium species were well represented.

Environmental groups were highly represented in the Bacteroidetes phylum (Figure 4C; Figure S7 in Supplementary Material), especially VadinHA17, WCHB1-69, and U29-B03 within the Rikenellaceae family. The pyrotags and clones revealed other environmental groups such as the M2PB4-65_termite_group (Hongoh et al., 2005) and ML635J-40_aquatic_group from Mono Lake (Humayoun et al., 2003) and PHOS-HE51 (Dabert et al., 2001).

Microbes classified in the Comamonadaceae family within the Beta-Proteobacteria, Rhizobiales order within Alpha-Proteobacteria and a Delta-Proteobacteria environmental group Sh765B-TzT-29 


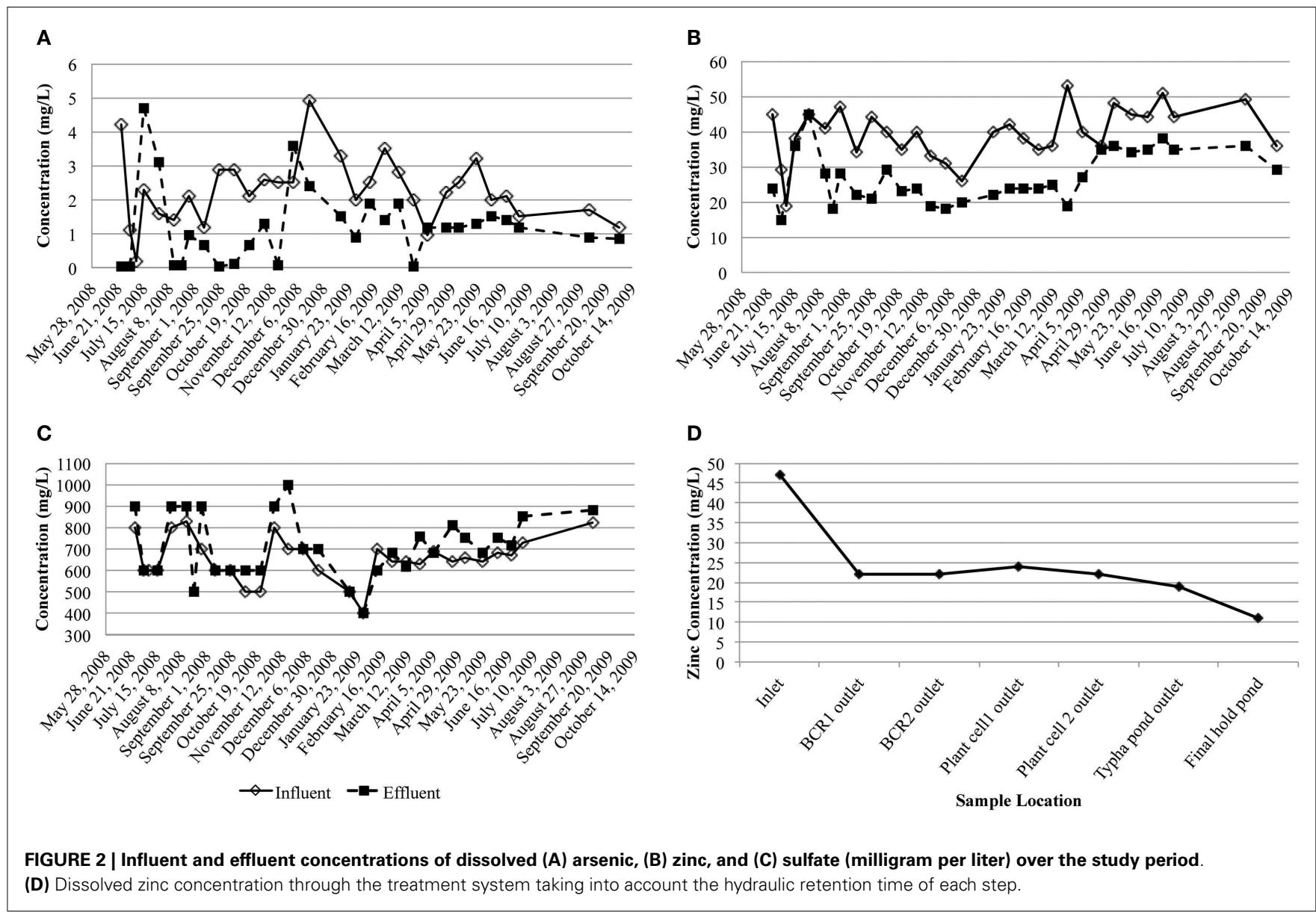

were the most important Proteobacteria (Figure 4D; Figure S8 in Supplementary Material). Two particularly predominant OTUs classified as Rhodobium/Hyphomicrobium (Figures S4 and S8 in Supplementary Material). At the time of writing, there were 44 environmental clones in the NCBI nucleotide database that were closely related to the predominant BCR Rhodobiumclassified clone ( $>97 \%$ identity). Of these, 17 came from wetland soils, 11 from natural or agriculture soils, 12 from contaminated soils (mining, radioactive waste, and HCs) and 4 from marine and cold-water sediments. OTUs classified in the environmental group Sh765B-TzT-29 were phylogenetically distinct from all the other Proteobacteria sequences (Figure S8 in Supplementary Material). Putative sulfate-reducing bacteria were rare, with some pyrotag sequences classified as Desulfovibrio and Desulfobulbus genera (Table S1 in Supplementary Material). Clostridia-related OTUs classified as Desulfosporosinus and Desulfotomaculum were present also (Table S1 in Supplementary Material).

Armatimonadetes-related reads were predominant (Figures S4 and S9 in Supplementary Material). At the time of writing, there were no other environmental clones more than $94 \%$ homologous to the bioreactor Armatimonadetes-related clone. Fibrobacteres (Fibrobacter), Planctomycetes (AKAU3564 sediment group), and Synergistetes (Synergistaceae) were three other phyla well represented in the bioreactor.

\section{CORRELATION OF MICROBIAL COMMUNITY WITH ORGANIC MATTER} CHARACTERISTICS

The $94 \%$ homology cut-off OTUs were rarefied to 4995 reads each per sample and then trimmed to exclude low diversity OTUs that were represented by fewer than three read counts and present in less than $20 \%$ of the samples. Comparison of sample microbial communities using weighted UniFrac analysis revealed two broad groups that appeared to cluster according to their ratio of PC to TOC (PC/TOC) (Figure S10 in Supplementary Material). Unifrac distances could not be used for correlation with the organic matter characteristics and Bray-Curtis dissimilarity indices based on OTU read counts were used instead (Figure 5A). Using a general linear model to fit the Bray-Curtis dissimilarities to the organic matter characteristics, a statistically significant correlation was revealed with the fraction of PC or RC $(p$-values $<0.001)$, and to a lesser extent the $\mathrm{S} 1$ fraction ( $p$-value $<0.5$; Table 3$)$. No statistically significant correlations were found between the microbial community composition and any of the pore water chemistry parameters (Table 1).

Prevalent OTUs and their taxonomic classifications were layered on to the same DCA plot for further interrogation of the phylogeny associated with more pyrolyzable or RC (Figure 5B; Figure S11 in Supplementary Material). Methanocorpusculum and VadinHA17 clustered together with samples containing more RC, whereas Ruminococcaceae were more likely to be found with higher 
Table 1 | Pore water chemistry for each of the boreholes at the time of sampling.

\begin{tabular}{|c|c|c|c|c|c|c|c|c|c|}
\hline \multirow{2}{*}{$\begin{array}{l}\text { Date } \\
\text { Hole number }\end{array}$} & \multicolumn{3}{|c|}{ July 2008} & \multicolumn{3}{|c|}{ April 2009} & \multicolumn{3}{|c|}{ October 2009} \\
\hline & 1 & 2 & 3 & 1 & 2 & 3 & 1 & 2 & 3 \\
\hline \multicolumn{10}{|c|}{ Pore water parameters measured in situ } \\
\hline Dissolved oxygen (mg/L) & 0.0 & 0.0 & 0.0 & 1.5 & 1.1 & 0.7 & 1.2 & 1.3 & 1.3 \\
\hline $\mathrm{pH}$ & 5.6 & 5.6 & 6.9 & 6.9 & 6.9 & 7.0 & 6.7 & 6.2 & 7.5 \\
\hline Oxidation/reduction potential (mV) & -133 & -112 & -238 & na & na & na & -118 & -244 & -130 \\
\hline Temperature $\left({ }^{\circ} \mathrm{C}\right)$ & 17.6 & 15.9 & 19.4 & 7.6 & 6.5 & 7.1 & 11.2 & 11.5 & 11.2 \\
\hline \multicolumn{10}{|l|}{ Dissolved metals (mg/l) } \\
\hline As & 0.19 & 0.06 & 0.03 & $0.94^{a}$ & 0.94 & 0.94 & 0.14 & 0.21 & 0.51 \\
\hline $\mathrm{Cd}$ & 0.06 & 0.02 & 0.01 & 0.002 & 0.002 & 0.002 & 0.0006 & 0.0012 & 0.055 \\
\hline $\mathrm{Mn}$ & 78 & 110 & 3.9 & 7.6 & 7.6 & 7.6 & 1.5 & 22 & 5.7 \\
\hline $\mathrm{Fe}$ & 740 & 910 & 50 & 7.6 & 7.6 & 7.6 & 1 & 4.25 & 0.3 \\
\hline $\mathrm{Sb}$ & 0.01 & 0.01 & 0.01 & 0.014 & 0.014 & 0.014 & 0.0028 & 0.002 & 0.0011 \\
\hline $\mathrm{Zn}$ & 6.1 & 1.3 & 0.52 & 0.058 & 0.058 & 0.058 & 0.045 & 0.093 & 0.28 \\
\hline \multicolumn{10}{|c|}{ Nutrients measured with chemets and hach kits (mg/l) } \\
\hline Sulfide & 1.1 & 2.6 & 3.45 & 0 & 0 & 0 & 0 & 0 & 0 \\
\hline Total phosphorous & 21 & 20 & 30 & 0.5 & 0.5 & 0.5 & 24 & 14 & 6.3 \\
\hline Sulfate & 200 & 80 & 150 & 470 & 470 & 470 & 600 & 150 & 270 \\
\hline Nitrite/nitrate & na/5.2 & na & na & $0.015 / 1.3$ & $0.015 / 1.3$ & $0.015 / 1.3$ & $0.023 / 5.5$ & $0.109 / 5.5$ & $0.01 / 1.5$ \\
\hline Ammonium-N & 460 & 340 & 490 & 61 & 61 & 61 & 60 & 76 & 36 \\
\hline \multicolumn{10}{|l|}{ Core solids chemistry } \\
\hline Total C (\%) & 9.39 & 10.65 & 6.23 & NSS & 10.6 & 18.3 & 18.3 & 7.12 & 3.32 \\
\hline Total S (\%) & 0.24 & 0.19 & 0.11 & NSS & 0.31 & 0.27 & 0.27 & 0.15 & 0.09 \\
\hline As (ppm) & 2.7 & 2.9 & 1.8 & $>250$ & 16.6 & 18.9 & 45.8 & 9.3 & 18.9 \\
\hline Cd (ppm) & 1.7 & 2 & 1.6 & 59.4 & 2.8 & 2.8 & 4.7 & 1.1 & 3.7 \\
\hline Zn (ppm) & 108 & 122 & 18.6 & 1735 & 180 & 177 & 705 & 127 & 380 \\
\hline Loss on ignition $\left(\% ; 1,000^{\circ} \mathrm{C}\right)$ & 25 & 29.5 & 118 & NSS & 24.8 & 30.1 & 38.7 & 23.1 & 8.49 \\
\hline
\end{tabular}

na, not available; NSS, not enough sample for the analysis.

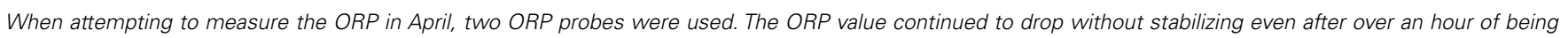
immersed in the pore water or lysimeter water.

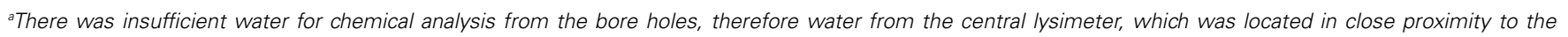
boreholes, at the same depth as the bore holes was analyzed instead.

amounts of PC. Proteobacteria OTUs such as those classified as Rhodobium, Hyphomicrobium, and Sh765B-TzT-29 appeared more so in the samples with higher PC content.

Correlation of microbial community structure with organic matter characteristics was tested for each of the months separately (Figure S12 in Supplementary Material). Statistically significant fits of microbial community composition with RockEval-6 variables PC and, to a lesser extent, S1 were obtained for the July and October samples, but not with the April samples. The prevalent OTUs clustered similarly in the July and October samples.

Co-occurrence of taxa in these specific clusters was confirmed with Pearson's correlation analysis (Figure S13 in Supplementary Material). Prevalent Proteobacteria-, Firmicutes- (Ruminococcaceae), and Actinobacteria-related OTUs co-occurred with each other (Pearson's correlation coefficient $>0.8, p$-value $<0.01$ ). OTU read counts plotted versus $\mathrm{PC} / \mathrm{TOC}$ fraction confirmed prevalence of the most abundant Methanocorpusculum- and VadinHA17related OTUs with the samples containing more recalcitrant organic matter, and the greater prevalence of Proteobacteria and Ruminococcaceae where there was more PC (Figure 6).

\section{DISCUSSION}

Important sustainable mechanisms for metal removal in BCRs are microbially driven. Detailed analysis of the microbial communities in these systems can be done using molecular surveys of the SSU rRNA gene. This reveals insight into the metabolic potential inside the bioreactor, and correlation of community composition with environmental and operational parameters provides valuable information on possible causes of metabolic shifts that may impact bioreactor performance. Reactors of this type are not perfectly mixed and environmental conditions inside the reactor might be heterogeneous. Additionally, they operate all year round and temporal shifts might influence the metabolic potential. For these reasons, samples taken across spatial and temporal gradients were needed to characterize the microbial community. The affordability and high-throughput of next generation sequencing enabled us to do this for the first time 
Table 2 | Rock-Eval results for the core samples.

\begin{tabular}{|c|c|c|c|c|c|c|c|c|c|c|}
\hline Sample ID & $\begin{array}{l}\text { Month } \\
\text { collected }\end{array}$ & Hole no. & $\begin{array}{l}\text { Depth } \\
\text { cm }\end{array}$ & $\begin{array}{l}\text { S1/TOC } \\
\text { (mg- }\end{array}$ & $\begin{array}{l}\text { S2/TOC } \\
\text { TOC) }\end{array}$ & PC/TOC & $\begin{array}{l}\text { RC/TOC } \\
\text { (fraction) }\end{array}$ & MINC/TOC & $T_{\max }$ & $T_{\text {peak }}$ \\
\hline TC1 & July & 1 & $0-10$ & 166 & 306 & 0.447 & 0.553 & 1.4 & 316 & 354 \\
\hline TC3 & July & 1 & 20-30 & 154 & 316 & 0.448 & 0.552 & 0.6 & 324 & 362 \\
\hline TC4 & July & 1 & $30-40$ & 104 & 268 & 0.394 & 0.606 & 5.6 & 330 & 368 \\
\hline TC7 & July & 1 & $10-20$ & 149 & 276 & 0.399 & 0.601 & 1.5 & 318 & 356 \\
\hline TC8 & July & 2 & $20-30$ & 147 & 286 & 0.403 & 0.597 & 1.2 & 323 & 361 \\
\hline TC9 & July & 2 & $30-40$ & 138 & 287 & 0.395 & 0.605 & 2.1 & 313 & 351 \\
\hline TC10 & July & 2 & $40-50$ & 134 & 282 & 0.389 & 0.611 & 0.6 & 324 & 362 \\
\hline TC11 & July & 3 & $0-10$ & 135 & 294 & 0.398 & 0.602 & 0.5 & 315 & 353 \\
\hline TC16 & April & 1 & $0-10$ & 90 & 255 & 0.346 & 0.654 & 1.1 & 314 & 352 \\
\hline TC17 & April & 1 & $10-20$ & 108 & 243 & 0.338 & 0.662 & 1.3 & 317 & 355 \\
\hline TC18 & April & 1 & 20-30 & 127 & 260 & 0.363 & 0.638 & 0.5 & 316 & 354 \\
\hline TC19 & April & 1 & $30-40$ & 126 & 277 & 0.384 & 0.616 & 1.5 & 312 & 350 \\
\hline TC22 & April & 2 & $20-30$ & 164 & 307 & 0.448 & 0.552 & 0.7 & 320 & 358 \\
\hline TC24 & April & 3 & $0-10$ & 148 & 307 & 0.422 & 0.578 & 0.6 & 319 & 357 \\
\hline TC25 & April & 3 & $10-20$ & 143 & 288 & 0.406 & 0.594 & 1.4 & 331 & 369 \\
\hline TC26 & April & 3 & $20-30$ & 133 & 266 & 0.366 & 0.634 & 0.4 & 316 & 354 \\
\hline TC27 & April & 3 & $30-40$ & 136 & 273 & 0.378 & 0.622 & 0.5 & 329 & 367 \\
\hline TC28 & October & 1 & $0-10$ & 104 & 289 & 0.379 & 0.621 & 6.6 & 314 & 352 \\
\hline \multirow[t]{5}{*}{ TC38 } & October & 3 & $20-30$ & 102 & 313 & 0.391 & 0.609 & 0.6 & 321 & 359 \\
\hline & & & Min. & 90 & 243 & 0.338 & 0.552 & 0.1 & 312 & 350 \\
\hline & & & Max. & 166 & 329 & 0.448 & 0.662 & 6.6 & 338 & 376 \\
\hline & & & Ave. & 131 & 291 & 0.400 & 0.600 & 1.3 & 320 & 358 \\
\hline & & & Std. dev. & 20 & 21 & 0.030 & 0.030 & 1.5 & 6 & 6 \\
\hline
\end{tabular}

for a bioreactor of this type. Sequencing revealed consistency in terms of the taxonomic groups represented over depth and season, with some variations in their proportional representation. In particular, some niches inside the BCR were dominated by methanogens. This was not expected. High concentrations of sulfate were measured in the bioreactor influent and in the pore water during sampling. If sulfate is non-limiting, sulfate-reducers are expected to outcompete methanogens due to thermodynamic favorability for sulfate-reduction (Raskin et al., 1996). Although these observations have held true for active bioreactors receiving defined-carbon sources (Dar et al., 2008), co-occurrence of methanogens and SRB has been observed in complex carbon bioreactors (Logan et al., 2003; Rezadehbashi and Baldwin, 2014).
It is not uncommon for sulfate-reducers to form only a small portion of the bacterial community in complex organic matter BCRs, since most microbes present in these bioreactors have the metabolic potential for organic matter degradation (Schmidtova and Baldwin, 2011). Even in the case of a defined-carbon source bioreactor, sulfate-reducers comprised less than $10 \%$ of all bacteria (Kaksonen et al., 2006). Very few studies are available on the microbial community composition of metal-treating complex carbon BCRs that have been operating in the field. Hiibel et al. (2008) surveyed the bacterial community of two pilot-scale fieldbased bioreactors treating acid mine drainage using $16 \mathrm{~S}$ rRNA clone libraries, but they did not include Archaea in their survey. Unpublished work from our laboratory indicates that in 


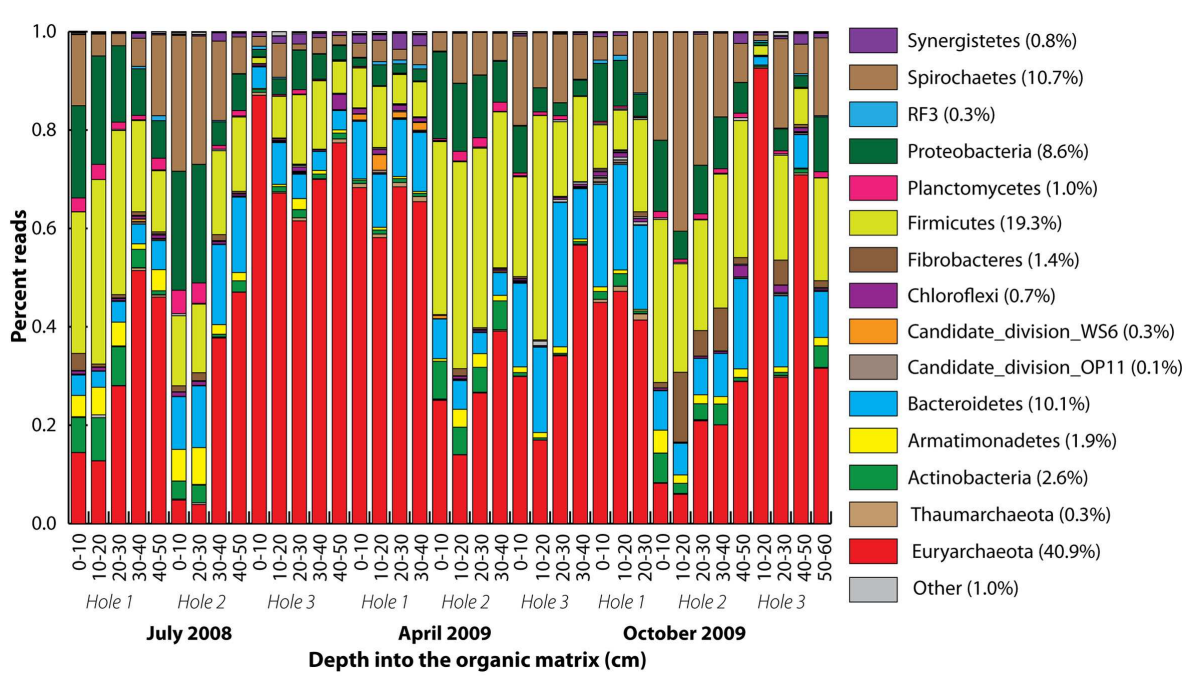

FIGURE 3 | Phylum-level taxonomic summary of $\mathbf{9 0} \%$ homology cut-off pyrotag reads. Phyla stacked according to color from the bottom to the top, starting with Euryarchaeota. Rare phyla were all colored gray (other). Vertical axis represents percent reads, and the horizontal axis depth (centimeter) into the organic matrix.

some field-based BCRs, sulfate-reducers are more abundant than methanogens (Rezadehbashi and Baldwin, 2014).

Although sulfate-reducers were rare at the time of this study, and restricted to only a few lineages, there was evidence for sulfide reduction: sulfide was detected in the BCR pore water during the summer. The chemical environment of the bioreactor was not toxic for sulfate-reducers as fresh organic materials of different types suspended in the bioreactor pore water were able to support a wide diversity of sulfate-reducing bacteria (Schmidtova and Baldwin, 2011). There is evidence that sulfate-reducers were more active in the BCR in the past. A mineralogical survey of the same BCR core samples as were used in this study revealed that As and $\mathrm{Zn}$ were present mostly as sulfides inside the bioreactor (Khoshnoodi et al., 2013). Data collected by the operators from previous years shows that sulfate was being reduced through the system (Mattes et al., 2011). According to influent and effluent chemical analysis performed by the operators, sulfate-reduction was not occurring in the BCR during the study period, thus it might have been the case that this system was shifting from sulfidogenesis to methanogenesis.

A pyrolysis-based technique proved to be useful for characterizing the degree of degradation of organic matter in the BCR. Other studies have used Rock-Eval to characterize soil organic matter. Deconvolution of the S2 peak revealed several overlapping peaks due to different classes of chemical compounds releasing at different temperatures (Sebag et al., 2006; Carrie et al., 2012). $T_{\text {peak }}$ values can be used to indicate the type of dominant organic matter in the mixture. Cellulose and lignin produce a peak at around $350^{\circ} \mathrm{C}$ when pyrolyzed as pure forms (Disnar et al., 2003). Thus, in the BCR core samples, the main S2 peak likely was due to pyrolysis of polysaccharides, polypeptides, and lignin. This main peak was more pronounced in the samples containing more PC (Figure S2C in Supplementary Material). Low molecular weight bioploymers such as sugars and lipids that are more biodegradable contribute to the S1 peak (Sebag et al., 2006; Carrie et al., 2012). Statistically significant correlation of microbial community structure with Rock-Eval-6 PC, and to a lesser degree the $S 1$ peak, suggested that the availability of organic matter may have been playing role in shifting of the BCR metabolic potential toward favoring methanogens. Association of methanogens with highly degraded environments was further supported in that close relatives to the BCR methanogens came from highly degraded carbon environments. The BCR was dominated by hydrogenotrophic methanogens (Methanocorpusculaceae and Methanobacteriaceae), although some acetoclastic groups were also present (i.e., Methanosarcina sp.). Rhodobium-related species have been found to be involved in dark carbon fermentation, which produces hydrogen (Patel and Kalia, 2013). OTUs in the BCR related to Rhodobium species, and Bacteroidetes, Firmicutes, Spirochetes, and Synergistetes-related OTUs that clustered with low PC and methanogen-enriched samples, likely include candidates for methanogen syntrophy. Thus, one metabolic cycle in the BCR potentially revolves around hydrogen and methane, which is analogous to what has been reported for highly degraded oil reservoirs where Rhizobiales have also been found to be abundant microbes together with methanogens (Zhang et al., 2012). Rhizobiales species are capable of arsenic resistance (Lim et al., 2014) and their relatives in the BCR may also have metal resistance pathways. Additionally, Hyphomicrobium spp. are methylotrophic (grow on $\mathrm{C} 1$ carbon compounds) and their relatives present in the BCR might have been involved in methane metabolism (Costa et al., 2000). The closest cultured relative to the BCR Hyphomicrobium-classified OTUs, $H$. vulgare, is prevalent in denitrifying bioreactors fed with methanol. Nitrate was present in the BCR feed water (average of $68.5 \pm 14 \mathrm{mg} / \mathrm{L}$ in July 2008 and average of $35.8 \pm 9 \mathrm{mg} / \mathrm{L}$ in April 2009). The availability of methane and nitrate may explain the prevalence of this group in the BCR. 


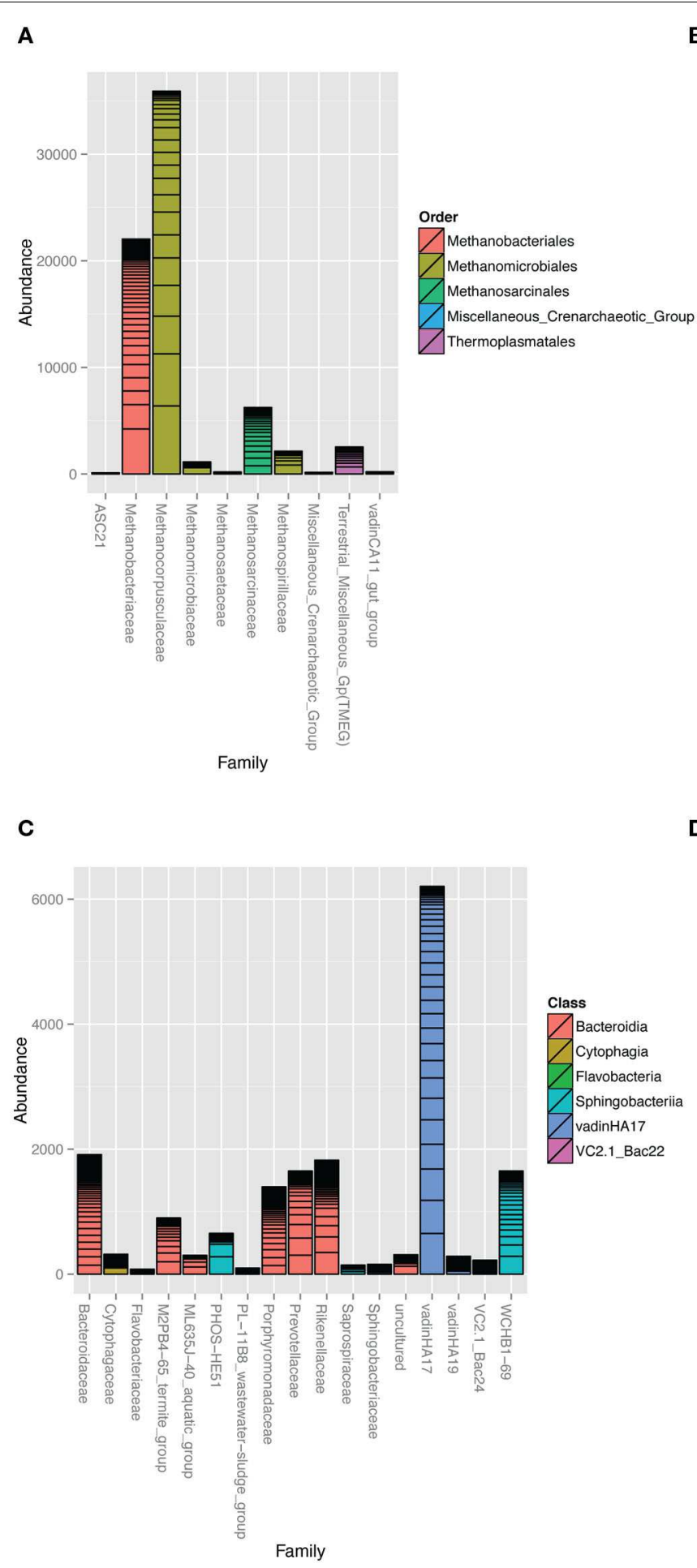

FIGURE 4 | Taxonomic summaries of read counts assigned to different families in the (A) Archaea domain and (B) Firmicutes, (C) Bacteroidetes, and (D) Proteobacteria phyla. Bars represent $90 \%$ homology cut-off OTUs stacked according to their abundance. Family bars are colored according to
B

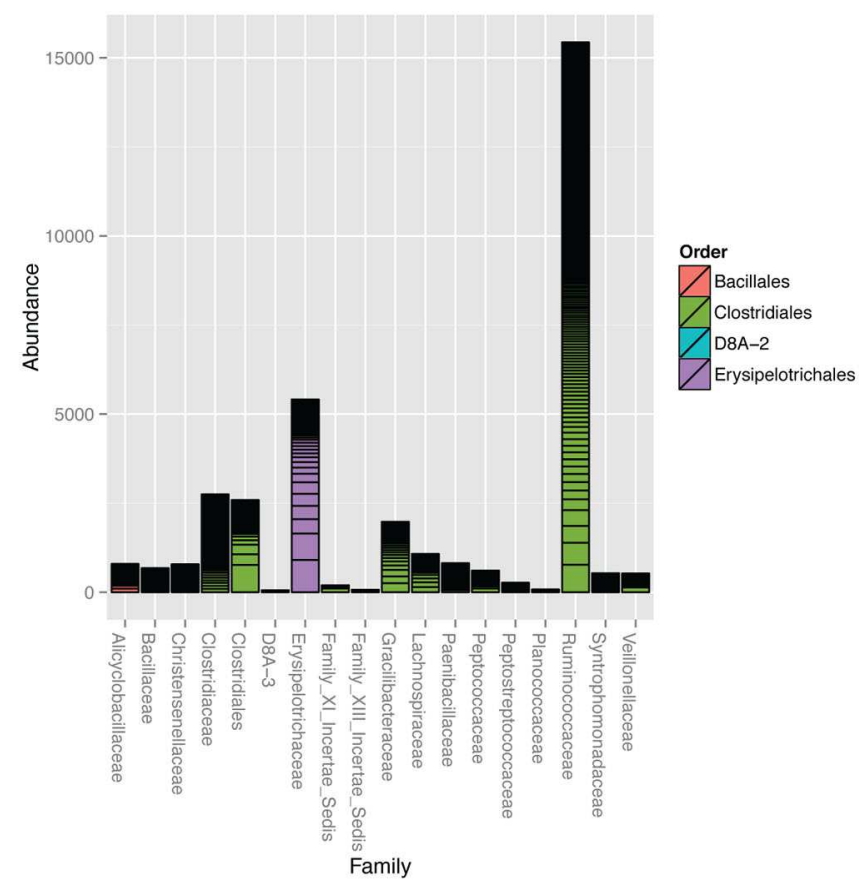

D

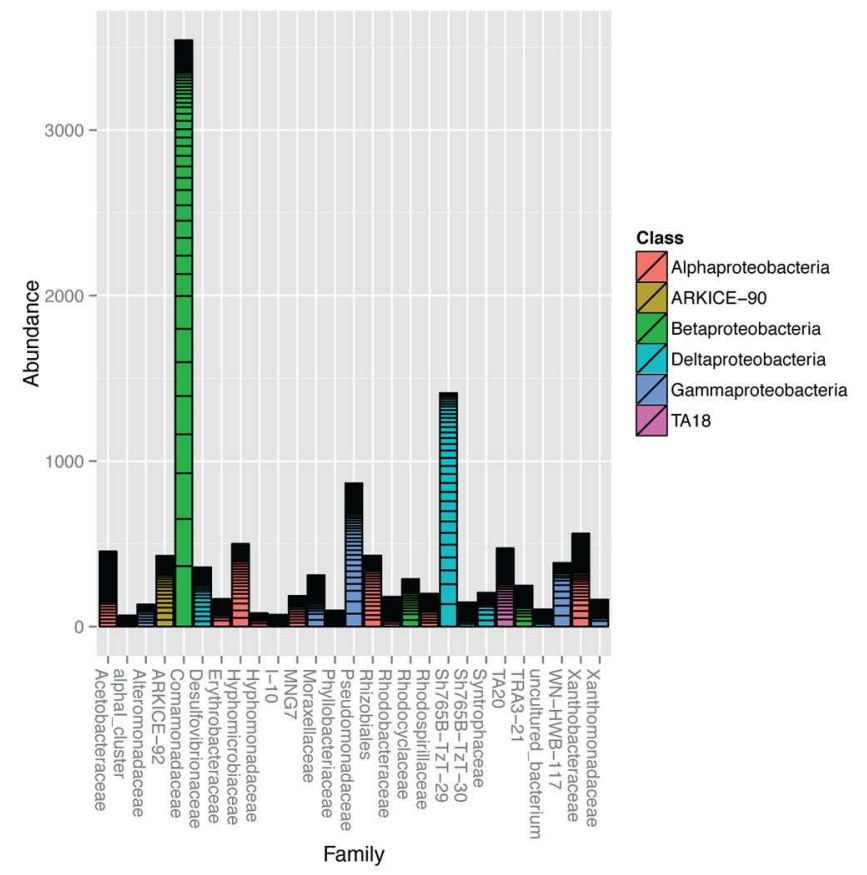

order. Vertical axis represents the number of pyrotag reads assigned to each family-level OTU. Barplots were constructed with the phyloseq

(http://joey711.github.io/phyloseq/) suite of packages and dependencies in R version 2.15.2.
Many bacteria classified in the phylum Proteobacteria are important for metal biotransformation. Although the BCR Comamonadaceae OTUs were unclassified, some were related to genera associated with anaerobic arsenite oxidation (e.g., Acidovorax; Huang et al., 2012). Sulfate-reducers detected in the BCR were classified in taxa (Desulfovibrionaceae, Desulfosporosinus, and 


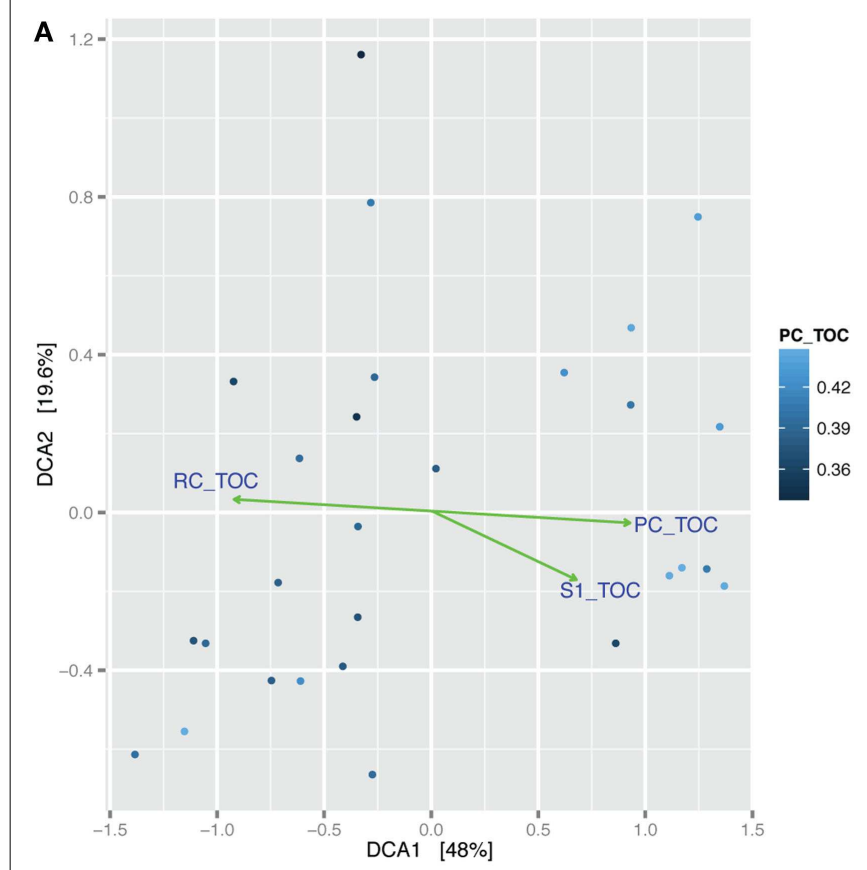

FIGURE 5 | Bray-Curtis dissimilarity detrended correspondence analysis (DCA) comparison of microbial communities in the samples. (A) Samples are shaded according to the fraction of pyrolyzable carbon to total organic carbon (PC/TOC). Green lines and arrows indicate statistically significant correlation of Bray-Curtis dissimilarity with fraction pyrolyzable carbon to total

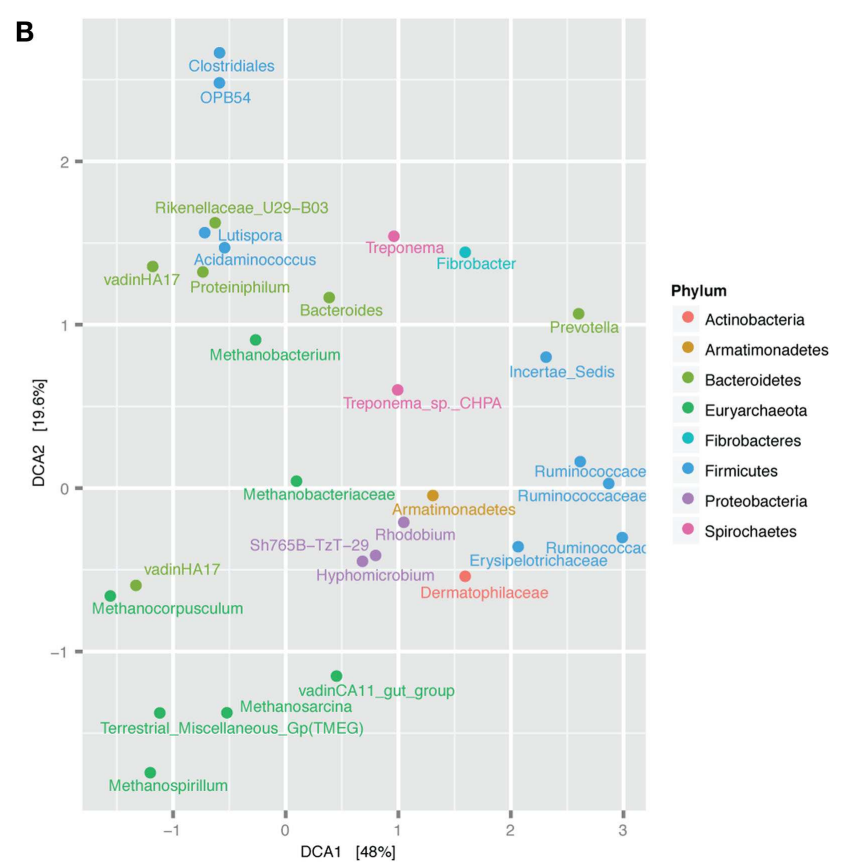

organic carbon. Samples containing more PC/TOC cluster on the right-hand side and those will more residual carbon (RC/TOC) cluster on the left-hand side. (B) Same analysis showing clustering of the top 30 most abundant OTUs with samples. OTUs (dots) labeled according to their lowest taxonomic assignment and colored according to Phylum.
Desulfotomaculum) also found in other high metal environments (Lee et al., 2009; Sánchez-Andrea et al., 2011). However, the most prevalent Delta-Proteobacteria found in the BCR, the environmental group Sh765B-TzT-29, had not been associated with these types of bioreactors until this study. This group was first assigned to Geobacteraceae as a cluster of heavy metal-associated microbes, and recently has been linked tentatively to methane oxidation in culturing experiments (Siegert et al., 2011). It is unknown if Sh765B-TzT-29 plays any role in the sulfur cycle.

The BCR contained other novel taxonomic groups that were predominant but whose role is unknown, such as those classified as Erysipelotrichaceae. Genera within these families are predominant gut bacteria, some of which are associated with high fat diets (Zhang et al., 2010). Members of the Bacteroidetes environmental groups VadinHA17, WCHB1-69, and U29-B03, also predominant in the BCR, are found in environments undergoing complex carbon degradation. Clone VadinHA17 came from an anaerobic digester treating winery wastewater (NCBI accession number U81712). The first member of WCHB1-69 was a clone found in an aquifer contaminated with HCs and chlorinated-solvents that was undergoing intrinsic bioremediation (NCBI accession number AF050545; Dojka et al., 1998). Most sequences classified in U29-B03 are from rumen environments according to the Silva SSU r117 database. Other Bacteroidetes-related OTUs were closely related to cultured species that produce acetate, $\mathrm{H}_{2}, \mathrm{CO}_{2}$, and possibly volatile sulfur compounds using elemental sulfur or nitrate as electron acceptors (Grabowski et al., 2005b; Krespi et al., 2006).
Table 3 | Statistical results of the linear fit of microbial community dissimilarities according to Bray-Curtis indices to organic matter characteristics as determined by Rock-Eval-6 variables in Table 2.

\begin{tabular}{lrrllc}
\hline Variable & DCA1 & DCA2 & $\boldsymbol{R}^{\mathbf{2}}$ & $\boldsymbol{p}$-Value & Significance \\
\hline S1/TOC & 0.697 & -0.717 & 0.240 & 0.024 & $\mathrm{a}$ \\
S2/TOC & 0.826 & -0.564 & 0.122 & 0.201 & \\
PC/TOC & 0.726 & -0.688 & 0.343 & 0.005 & $\mathrm{~b}$ \\
RC/TOC & -0.726 & 0.698 & 0.343 & 0.005 & $\mathrm{~b}$ \\
MINC/TOC & -0.100 & -0.995 & 0.087 & 0.345 & \\
\hline
\end{tabular}

Significance codes:

${ }^{a}<0.05$;

${ }^{b}<0.01$.

p-Value based on 999 permutations.

Overall, the microbial community in the BCR consisted of highly specialized groups closely related to other organisms associated with metal-rich environments as well as highly degraded HC reservoirs experiencing terminal carbon degradation by methanogens and possibly microbes within the Rhizobiales order. Predominant taxonomic groups revealed metabolic potential for methane production, metal-tolerance, and resistance, and many different types of fermentation including possibly dark fermentation to produce hydrogen. Sulfate-reduction potential according to known SRB taxonomic groups was less represented. Novel groups 


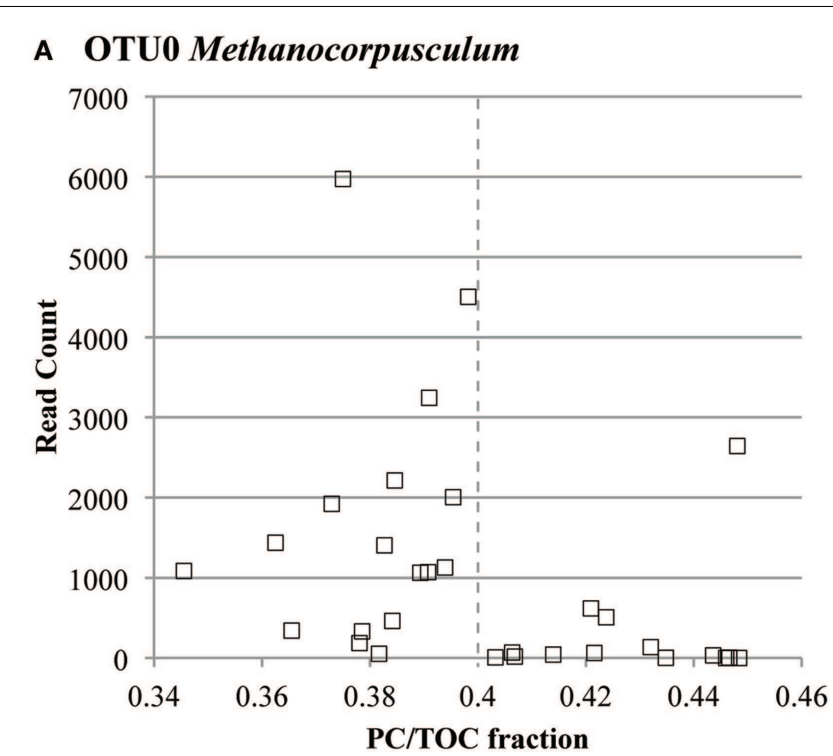

C Total Proteobacteria

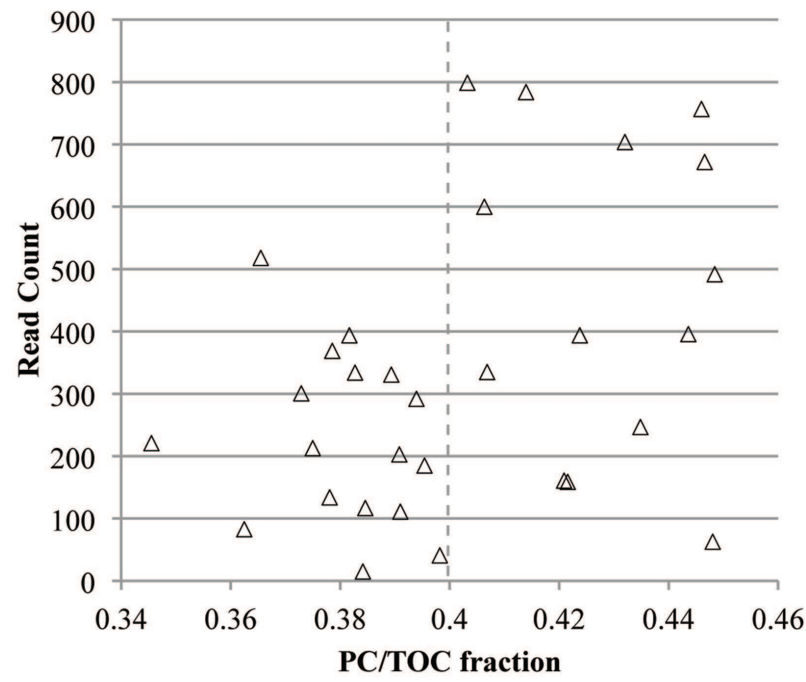

FIGURE 6 | OTU read count versus ratio of pyrolyzable carbon to total organic carbon (PC/TOC) for select highly prevalent taxa: (A) OTUO classified as Methanocorpusculum related, (B) OTU9 classified in the

predominant within the BCR may contain organisms involved in sulfur cycling and metal resistance. The microbial community broadly delineated according to the degree of organic matter degradation with methanogens and putative syntrophs, dominant in more recalcitrant material and Proteobacteria, Actinobacteria, Armatimonadetes, and Planctomycetes prevalent in places with more PC.

\section{CONCLUSION}

This work has contributed to opening the "black box" of bioremediation of metal and sulfate-contaminated water. It was revealed for this particular system that sulfate-reducers, desired for metal sulfide precipitation, were rare and restricted to a few specific genera: Desulfobulbus, Desulfovibrio, Desulfosporosinus,

\section{в OTU9_VadinHA17}

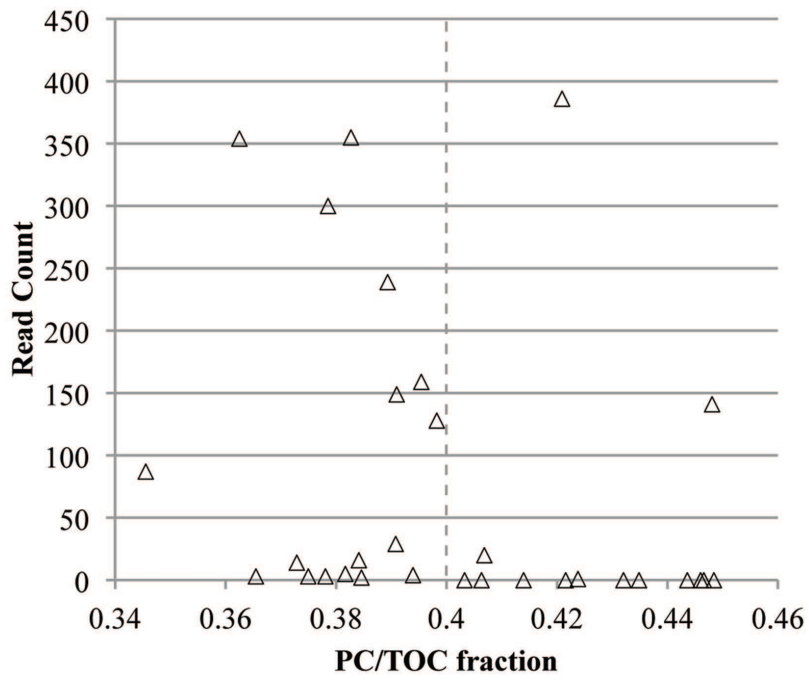

D Ruminococcaceae

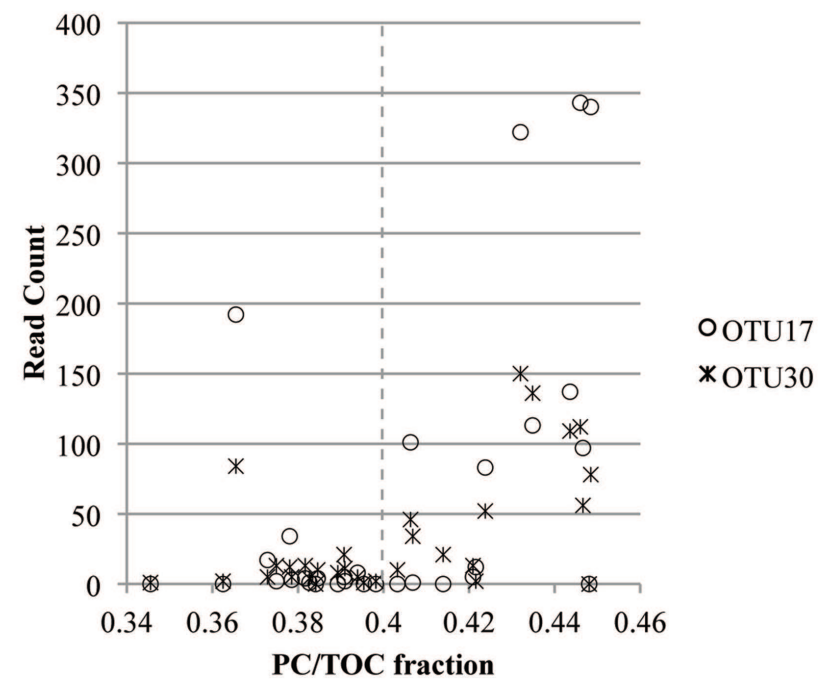

environmental group VadinHA17, (C) all OTUs classified in the Proteobacteria phylum and (D) OTUs 17 and 30 classified in the Ruminococcaceae family.

and Desulfotomaculum. The bioreactor was dominated by methanogens, with a Methanocorpusculum-related OTU most prevalent. Correlation of methanogen-related OTUs with more degraded material suggests that as these types of bioreactors age, methanogens might become more prevalent. Many novel, uncharacterized taxonomic groups were found and suggest that the metabolic potential for organic matter degradation or even metal transformation is much more diverse than previously thought.

\section{AUTHOR CONTRIBUTIONS}

The manuscript was written through contributions of all authors. All authors have given approval to the final version of the manuscript. 


\section{ACKNOWLEDGMENTS}

This work was supported by Genome British Columbia Applied Genomics Innovation Program Grant 108-ROC to SB, Natural Science and Engineering Research Council Collaborative Research and Development Grant CRDPJ 364108 - 07 to SB, and direct and in-kind funding from the following companies: Teck Metals Limited, Vancouver, BC, Canada; Imperial Metals Corporation, Vancouver, BC, Canada; NatureWorks Remediation Corporation, Rossland, BC, Canada.

\section{SUPPLEMENTARY MATERIAL}

The Supplementary Material for this article can be found online at http://www.frontiersin.org/Journal/10.3389/fbioe.2015.00027/ abstract

This includes details of the molecular biology materials and methods, a table of the putative sulfate-reducing bacteria found in the BCR pyrotag library, a table of the highly correlated cooccurring OTUs, a simple cartoon of the BCR, details for the Rock-Eval-6 analysis, phylogenetic trees clone library SSU rRNA $97 \%$ homology cut-off OTUs, charts of the relative abundance of the most highly prevalent pyrotag OTUs, UniFrac principal component analysis of the microbial communities, Bray-Curtis dissimilarity detrended correspondence analysis of microbial communities faceted according to Phylum, Bray-Curtis dissimilarity detrended correspondence analysis of samples split according to season and a network of the most highly correlated OTUs.

\section{REFERENCES}

Amoozegar, M. A., Khoshnoodi, M., Didari, M., Hamedi, J., Ventosa, A., and Baldwin, S. A. (2012). Tellurite removal by a tellurium-tolerant halophilic bacterial strain, Thermoactinomyces sp. QS-2006. Ann. Microbiol. 62, 1031-1037. doi:10.1007/s13213-011-0343-1

Behar, F., Beaumont, V., De, B., and Penteado, H. L. (2001). Rock-Eval 6 technology: performances and developments. Oil Gas Sci. Technol. 56, 111-134. doi: 10.2516/ogst:2001013

Bentley, R., and Chasteen, T. G. (2002). Microbial methylation of metalloids: arsenic, antimony, and bismuth. Microbiol. Mol. Biol. Rev. 66, 250-271. doi:10.1128/ MMBR.66.2.250-271.2002

Caporaso, J. G., Kuczynski, J., Stombaugh, J., Bittinger, K., Bushman, F. D., Costello, E. K., et al. (2010). QIIME allows analysis of high-throughput community sequencing data. Nat. Methods 7, 335-336. doi:10.1038/nmeth.f.303

Carrie, J., Sanei, H., and Stern, G. (2012). Standardisation of Rock-Eval pyrolysis for the analysis of recent sediments and soils. Org. Geochem. 46, 38-53. doi:10.1016/j.orggeochem.2012.01.011

Costa, C., Dijkema, C., Friedrich, M., García-Encina, P., Fernández-Polanco, F., and Stams, A. J. (2000). Denitrification with methane as electron donor in oxygen-limited bioreactors. Appl. Microbiol. Biotechnol. 53, 754-762. doi:10. $1007 / \mathrm{s} 002530000337$

Dabert, P., Sialve, B., Delgenès, J. P., Moletta, R., and Godon, J. J. (2001). Characterisation of the microbial $16 \mathrm{~S}$ rDNA diversity of an aerobic phosphorus-removal ecosystem and monitoring of its transition to nitrate respiration. Appl. Microbiol. Biotechnol. 55, 500-509. doi:10.1007/s002530000529

Dar, S. A., Kleerebezem, R., Stams, A. J. M., Kuenen, J. G., and Muyzer, G. (2008). Competition and coexistence of sulfate-reducing bacteria, acetogens and methanogens in a lab-scale anaerobic bioreactor as affected by changing substrate to sulfate ratio. Appl. Microbiol. Biotechnol. 78, 1045-1055. doi:10.1007/ s00253-008-1391-8

Dar, S. A., Yao, L., van Dongen, U., Kuenen, J. G., and Muyzer, G. (2007). Analysis of diversity and activity of sulfate-reducing bacterial communities in sulfidogenic bioreactors using $16 \mathrm{~S}$ rRNA and dsrB genes as molecular markers. Appl. Environ. Microbiol. 73, 594-604. doi:10.1128/AEM.01875-06

Dinis, J. M., Barton, D. E., Ghadiri, J., Surendar, D., Reddy, K., Velasquez, F., et al. (2011). In search of an uncultured human-associated TM7 bacterium in the environment. PLOS ONE 6:e21280. doi:10.1371/journal.pone.0021280
Disnar, J. R., Guillet, B., Keravis, D., Di-Giovanni, C., and Sebag, D. (2003). Soil organic matter (SOM) characterization by Rock-Eval pyrolysis: scope and limitations. Org. Geochem. 34, 327-343. doi:10.1016/S0146-6380(02)00239-5

Dojka, M. A., Hugenholtz, P., Haack, S. K., and Pace, N. R. (1998). Microbial diversity in a hydrocarbon- and chlorinated-solvent-contaminated aquifer undergoing intrinsic bioremediation. Appl. Environ. Microbiol. 64, 3869-3877.

Eaton, A. D., Clesceri, L. S., Rice, E. W., and Greedberg, A. E. (2005). Standard Methods for the Examination of Water and Wastewater, 21 Edition. Baltimore, MD: American Public Health Association; American Water Works Association; Water Environment Federation.

Edgar, R. C. (2004). MUSCLE: multiple sequence alignment with high accuracy and high throughput. Nucleic Acids Res. 32, 1792-1797. doi:10.1093/nar/gkh340

Edgar, R. C. (2010). Search and clustering orders of magnitude faster than BLAST. Bioinformatics 26, 2460-2461. doi:10.1093/bioinformatics/btq461

French, S., Puddephatt, D., Habash, M., and Glasauer, S. (2013). The dynamic nature of bacterial surfaces: implications for metal-membrane interaction. Crit. Rev. Microbiol. 39, 196-217. doi:10.3109/1040841X.2012.702098

Gadd, G. M. (2010). Metals, minerals and microbes: geomicrobiology and bioremediation. Microbiology 156, 609-643. doi:10.1099/mic.0.037143-0

Godon, J. J., Zumstein, E., Dabert, P., Habouzit, F., and Moletta, R. (1997). Molecular microbial diversity of an anaerobic digestor as determined by small-subunit rDNA sequence analysis. Appl. Environ. Microbiol. 63, 2802-2813.

Grabowski, A., Nercessian, O., Fayolle, F., Blanchet, D., and Jeanthon, C. (2005a) Microbial diversity in production waters of a low-temperature biodegraded oil reservoir. FEMS Microbiol. Ecol. 54, 427-443. doi:10.1016/j.femsec.2005.05.007

Grabowski, A., Tindall, B. J., Bardin, V., Blanchet, D., and Jeanthon, C. (2005b). Petrimonas sulfuriphila gen. nov., sp. nov., a mesophilic fermentative bacterium isolated from a biodegraded oil reservoir. Int. J. Syst. Evol. Microbiol. 55, 1113-1121. doi:10.1099/ijs.0.63426-0

Guindon, S., Delsuc, F., Dufayard, J.-F., and Gascuel, O. (2009). Estimating maximum likelihood phylogenies with PhyML. Methods Mol. Biol. 537, 113-137. doi:10.1007/978-1-59745-251-9_6

Hasegawa, M., Kishino, H., and Yano, T. (1985). Dating of the human-ape splitting by a molecular clock of mitochondrial DNA. J. Mol. Evol. 22, 160-174. doi:10.1007/BF02101694

Hiibel, S. R., Pereyra, L. P., Inman, L. Y., Tischer, A., Reisman, D. J., Reardon, K. F., et al. (2008). Microbial community analysis of two field-scale sulfatereducing bioreactors treating mine drainage. Environ. Microbiol. 10, 2087-2097. doi:10.1111/j.1462-2920.2008.01630.x

Hongoh, Y., Deevong, P., Inoue, T., Moriya, S., Trakulnaleamsai, S., Ohkuma, M., et al. (2005). Intra- and interspecific comparisons of bacterial diversity and community structure support coevolution of gut microbiota and termite host. Appl. Environ. Microbiol. 71, 6590-6599. doi:10.1128/AEM.71.11.6590-6599.2005

Huang, Y., Li, H., Rensing, C., Zhao, K., Johnstone, L., and Wang, G. (2012). Genome sequence of the facultative anaerobic arsenite-oxidizing and nitratereducing bacterium Acidovorax sp. strain NO1. J. Bacteriol. 194, 1635-1636. doi:10.1128/JB.06814-11

Humayoun, S. B., Bano, N., and Hollibaugh, J. T. (2003). Depth distribution of microbial diversity in Mono Lake, a meromictic soda lake in California. Appl. Environ. Microbiol. 69, 1030-1042. doi:10.1128/AEM.69.2.1030-1042.2003

Jalali, K., and Baldwin, S. A. (2000). The role of sulphate reducing bacteria in copper removal from aqueous sulphate solutions. Water Res. 34, 797-806. doi:10.1016/S0043-1354(99)00194-3

Jones, R. T., Robeson, M. S., Lauber, C. L., Hamady, M., Knight, R., and Fierer, N. (2009). A comprehensive survey of soil acidobacterial diversity using pyrosequencing and clone library analyses. ISME J. 3, 442-453. doi:10.1038/ ismej.2008.127

Kaksonen, A. H., Plumb, J. J., Robertson, W. J., Riekkola-Vanhanen, M., Franzmann, P. D., and Puhakka, J. A. (2006). The performance, kinetics and microbiology of sulfidogenic fluidized-bed treatment of acidic metal- and sulfate-containing wastewater. Hydrometallurgy 83, 204-213. doi:10.1016/j.hydromet.2006.03.025

Khoshnoodi, M., Dipple, G., and Baldwin, S. (2013). Mineralogical study of a biologically-based treatment system that removes arsenic, zinc and copper from landfill leachate. Minerals 3, 427-449. doi:10.3390/min3040427

Krespi, Y. P., Shrime, M. G., and Kacker, A. (2006). The relationship between oral malodor and volatile sulfur compound-producing bacteria. Otolaryngol. Head Neck Surg. 135, 671-676. doi:10.1016/j.otohns.2005.09.036

Lee, Y.-J., Romanek, C. S., and Wiegel, J. (2009). Desulfosporosinus youngiae sp. nov., a spore-forming, sulfate-reducing bacterium isolated from a constructed 
wetland treating acid mine drainage. Int. J. Syst. Evol. Microbiol. 59, 2743-2746. doi:10.1099/ijs.0.007336-0

Li, W., and Godzik, A. (2006). Cd-hit: a fast program for clustering and comparing large sets of protein or nucleotide sequences. Bioinformatics 22, 1658-1659. doi:10.1093/bioinformatics/btl158

Lim, K. T., Shukor, M. Y., and Wasoh, H. (2014). Physical, chemical, and biological methods for the removal of arsenic compounds. Biomed Res. Int. 2014, 503784 doi:10.1155/2014/503784

Lindsay, M. B. J., Ptacek, C. J., Blowes, D. W., and Gould, W. D. (2008). Zerovalent iron and organic carbon mixtures for remediation of acid mine drainage: batch experiments. Appl. Geochem. 23, 2214-2225. doi:10.1016/j.apgeochem. 2008.03.005

Lindsay, M. B. J., Wakeman, K. D., Rowe, O. F., Grail, B. M., Ptacek, C. J., Blowes, D. W., et al. (2011). Microbiology and geochemistry of mine tailings amended with organic carbon for passive treatment of pore water. Geomicrobiol. J. 28, 229-241. doi: $10.1080 / 01490451.2010 .493570$

Logan, M., Ahmann, D., and Figueroa, L. (2003). "Assessment of microbial activity in anaerobic columns treating synthetic mine drainage 1," in Joint Conference of the 9th Billings Land Reclamation Symposium and the 20th Annual Meetings of the American Society of Mining and Reclamation June 3-6, 2003 (Billings), 0658.

Lozupone, C., and Knight, R. (2005). UniFrac: a new phylogenetic method for comparing microbial communities. Appl. Environ. Microbiol. 71, 8228-8235. doi:10.1128/AEM.71.12.8228-8235.2005

Mattes, A., Evans, L. J., Gould, D. W., Duncan, W. F. A., and Glasauer, S. (2011). The long term operation of a biologically based treatment system that removes As, $\mathrm{S}$ and $\mathrm{Zn}$ from industrial (smelter operation) landfill seepage. Appl. Geochem. 26, 1886-1896. doi:10.1016/j.apgeochem.2011.06.012

McMurdie, P. J., and Holmes, S. (2013). phyloseq: an R package for reproducible interactive analysis and graphics of microbiome census data. PLoS One 8:e61217. doi:10.1371/journal.pone.0061217

Mullen, M. D., Wolf, D. C., Ferris, F. G., Beveridge, T. J., Flemming, C. A., and Bailey, G. W. (1989). Bacterial sorption of heavy metals. Appl. Environ. Microbiol. 55, 3143-3149.

Neculita, C. M., and Zagury, G. J. (2008). Biological treatment of highly contaminated acid mine drainage in batch reactors: long-term treatment and reactive mixture characterization. J. Hazard. Mater. 157, 358-366. doi:10.1016/j.jhazmat. 2008.01.002

Patel, S. K. S., and Kalia, V. C. (2013). Integrative biological hydrogen production: an overview. Indian J. Microbiol. 53, 3-10. doi:10.1007/s12088-012-0287-6

Pereyra, L. P., Hiibel, S. R., Pruden, A., and Reardon, K. F. (2008). Comparison of microbial community composition and activity in sulfate-reducing batch systems remediating mine drainage. Biotechnol. Bioeng. 101, 702-713. doi:10.1002/bit. 21930

Pruitt, K. D., Tatusova, T., Klimke, W., and Maglott, D. R. (2009). NCBI reference sequences: current status, policy and new initiatives. Nucleic Acids Res. 37, D32-D36. doi:10.1093/nar/gkn721

Quast, C., Pruesse, E., Yilmaz, P., Gerken, J., Schweer, T., Yarza, P., et al. (2013). The SILVA ribosomal RNA gene database project: improved data processing and web-based tools. Nucleic Acids Res. 41, D590-D596. doi:10.1093/nar/gks1219

Raskin, L., Rittmann, B. E., and Stahl, D. A. (1996). Competition and coexistence of sulfate-reducing and methanogenic populations in anaerobic biofilms. Appl. Environ. Microbiol. 62, 3847-3857.

Rezadehbashi, M., and Baldwin, S. A. (2014). "Q-1874. the co-occurrence of sulfatereducing microorganisms and methanogens in bioreactors treating metal and sulfate containing mine-affected water," in American Society for Microbiology 114th General Meeting May 17-20 (Boston, MA: American Society for Microbiology), 182.

Sánchez-Andrea, I., Rodríguez, N., Amils, R., and Sanz, J. L. (2011). Microbial diversity in anaerobic sediments at Rio Tinto, a naturally acidic environment with a high heavy metal content. Appl. Environ. Microbiol. 77, 6085-6093. doi:10.1128/AEM.00654-11
Schloss, P. D., Westcott, S. L., Ryabin, T., Hall, J. R., Hartmann, M., Hollister, E. B., et al. (2009). Introducing mothur: open-source, platform-independent, community-supported software for describing and comparing microbial communities. Appl. Environ. Microbiol. 75, 7537-7541. doi:10.1128/AEM.01541-09

Schmidtova, J., and Baldwin, S. A. (2011). Correlation of bacterial communities supported by different organic materials with sulfate reduction in metal-rich landfill leachate. Water Res. 45, 1115-1128. doi:10.1016/j.watres.2010.10.038

Sebag, D., Disnar, J. R., Guillet, B., Di Giovanni, C., Verrecchia, E. P., and Durand, A. (2006). Monitoring organic matter dynamics in soil profiles by "Rock-Eval pyrolysis": bulk characterization and quantification of degradation. Eur. J. Soil Sci. 57, 344-355. doi:10.1111/j.1365-2389.2005.00745.x

Siegert, M., Krüger, M., Teichert, B., Wiedicke, M., and Schippers, A. (2011). Anaerobic oxidation of methane at a marine methane seep in a forearc sediment basin off Sumatra, Indian Ocean. Front. Microbiol. 2:249. doi:10.3389/fmicb.2011.00249

Stolz, J. F., Basu, P., Santini, J. M., and Oremland, R. S. (2006). Arsenic and selenium in microbial metabolism. Annu. Rev. Microbiol. 60, 107-130. doi:10.1146/ annurev.micro.60.080805.142053

Strapoc, D., Picardal, F. W., Turich, C., Schaperdoth, I., Macalady, J. L., Lipp, J. S., et al. (2008). Methane-producing microbial community in a coal bed of the Illinois basin. Appl. Environ. Microbiol. 74, 2424-2432. doi:10.1128/AEM.02341-07

Waybrant, K. R., Blowes, D. W., and Ptacek, C. J. (1998). Selection of reactive mixtures for use in permeable reactive walls for treatment of mine drainage. Environ. Sci. Technol. 32, 1972-1979. doi:10.1021/es9703335

Youssef, N. H., Blainey, P. C., Quake, S. R., and Elshahed, M. S. (2011). Partial genome assembly for a candidate division OP11 single cell from an anoxic spring (Zodletone Spring, Oklahoma). Appl. Environ. Microbiol. 77, 7804-7814. doi:10.1128/AEM.06059-11

Zagury, G. J., Kulnieks, V. I., and Neculita, C. M. (2006). Characterization and reactivity assessment of organic substrates for sulphate-reducing bacteria in acid mine drainage treatment. Chemosphere 64,944-954. doi:10.1016/j.chemosphere. 2006.01.001

Zhang, C., Zhang, M., Wang, S., Han, R., Cao, Y., Hua, W., et al. (2010). Interactions between gut microbiota, host genetics and diet relevant to development of metabolic syndromes in mice. ISME J. 4, 232-241. doi:10.1038/ismej.2009.112

Zhang, F., She, Y.-H., Chai, L.-J., Banat, I. M., Zhang, X.-T., Shu, F.-C., et al. (2012). Microbial diversity in long-term water-flooded oil reservoirs with different in situ temperatures in China. Sci. Rep. 2, 760. doi:10.1038/srep00760

Zhang, Y., and Frankenberger, W. T. (2000). Formation of dimethylselenonium compounds in soil. Environ. Sci. Technol. 34, 776-783. doi:10.1021/es990958y

Zhao, Y., Boone, D. R., Mah, R. A., Boone, J. E., and Xun, L. (1989). Isolation and characterization of Methanocorpusculum labreanum sp. nov. from the La Brea Tar Pits. Int. J. Syst. Bacteriol. 39, 10-13. doi:10.1099/00207713-39-1-10

Conflict of Interest Statement: The authors declare that the research was conducted in the absence of any commercial or financial relationships that could be construed as a potential conflict of interest.

Received: 26 October 2014; accepted: 19 February 2015; published online: 06 March 2015.

Citation: Baldwin SA, Khoshnoodi M, Rezadehbashi M, Taupp M, Hallam S, Mattes $A$ and Sanei $H$ (2015) The microbial community of a passive biochemical reactor treating arsenic, zinc, and sulfate-rich seepage. Front. Bioeng. Biotechnol. 3:27. doi: 10.3389/fbioe.2015.00027

This article was submitted to Microbiotechnology, Ecotoxicology and Bioremediation, a section of the journal Frontiers in Bioengineering and Biotechnology.

Copyright (C) 2015 Baldwin, Khoshnoodi, Rezadehbashi, Taupp, Hallam, Mattes and Sanei. This is an open-access article distributed under the terms of the Creative Commons Attribution License (CC BY). The use, distribution or reproduction in other forums is permitted, provided the original author(s) or licensor are credited and that the original publication in this journal is cited, in accordance with accepted academic practice. No use, distribution or reproduction is permitted which does not comply with these terms. 